\title{
Paradoxical response to nebulised salbutamol in wheezy infants, assessed by partial expiratory flow-volume curves
}

\author{
ANNE PRENDIVILLE, SALLY GREEN, MICHAEL SILVERMAN \\ From the Department of Paediatrics and Neonatal Medicine, Royal Postgraduate Medical School, \\ Hammersmith Hospital, London
}

ABSTRACT Lower airway responses to nebulised bronchodilators were studied in 18 chronically or recurrently wheezy infants, aged 3-15 months, by means of partial forced expiratory flow-volume manoeuvres performed with an inflatable jacket. Maximum flow at functional residual capacity (FRC) (VmaxFRC) was used as the index of intrathoracic airways function. Peak expiratory flow rate was also measured. Baseline airways resistance and lung volume were determined during quiet breathing in an infant whole body plethysmograph. Measurements were made on separate days before and after nebulised salbutamol $2.5 \mathrm{mg}$ with nebulised saline as control. The results were paradoxical: there was no change in $\dot{V}$ maxFRC after saline, but a significant decline in VmaxFR was found after salbutamol. Peak expiratory flow remained unchanged. These observations suggest that under conditions of forced expiration intrathoracic airways function may be further impaired by nebulised bronchodilator treatment in wheezy infants. When nebulised bronchodilator drugs are used to treat severe airways obstruction in infancy, careful monitoring is essential.

It is now widely believed that wheezy infants, in constrast with older children, do not respond to either of the two generally available classes of bronchodilator drugs, $\beta_{2}$ selective sympathomimetic agents and anticholinergic, antimuscarinic agents. Most physiological measurements ${ }^{1-3}$ and clinical trials ${ }^{34}$ have shown no significant effect, although a clinical benefit has been claimed for combination treatment with a $\beta_{2}$ sympathomimetic agent and a corticosteroid in acute bronchiolitis. ${ }^{5}$ The many reasons that have been put forward for the apparent lack of response include inadequate airway smooth muscle, insufficient or ineffective $\beta$ receptors, and inappropriate airway pathophysiology. ${ }^{6}$

One additional factor that has not been taken into account is the relative contribution of the upper airways to airways obstruction in wheezy infants. In the past, measurements of airways function in wheezy infants have been made during sleep, when it is reasonable to assume nasal breathing, and have therefore provided an overall value for upper and lower airways combined. Normally the nasal passages

Address for correspondence: Dr M Silverman, Department of Paediatrics and Neonatal Medicine, Hammersmith Hospital, London W12 0HS.

Accepted 30 September 1986 account for about half of the overall airways resistance in caucasian infants, ${ }^{7}$ while the glottis accounts for a further important proportion, especially in the presence of obstructive airways disease. ${ }^{89}$ Wheezy infants commonly suffer from upper airway obstruction, and so the upper airways resistance may contribute very considerably and very variably to measured values of airways resistance, masking any possible bronchial effects of inhaled drugs and possibly giving misleading results since these drugs also act on the upper airway. ${ }^{10}$

Forced expiratory flow-volume curves in older children and adults provide information about intrathoracic airways function independently of quite wide variations in glottic and nasal obstruction. A technique has recently been described for obtaining flow-volume curves during tidal breathing in sleeping infants, in which forced expiration is effected by thoracoabdominal compression. ${ }^{1112}$ We have applied this technique to study the effect of a single nebulised dose of salbutamol on intrathoracic airway function in infants with chronic or recurrent wheeze.

\section{Methods}

PATIENTS

A total of 18 infants aged 3-15 months completed 
both study days. All had a history of recurrent wheezing, but none had symptoms at the time of testing. Ten had a first degree relative with atopic disease; three had had acute bronchiolitis requiring hospital admission (and in two cases mechanical ventilation) at the onset of their chronic chest disorder, and three had been mechanically ventilated in the neonatal period for neonatal respiratory distress syndrome. None had evidence of cystic fibrosis, recurrent aspiration, or congenital abnormalities of the lungs or heart. Infants were studied after chloral sedation $(100 \mathrm{mg} / \mathrm{kg}$ orally) in an interval between acute attacks of wheeze and in the absence of appreciable nasal symptoms. The studies formed part of the clinical evaluation, for which their parents' consent was obtained.

\section{LUNG FUNCTION TESTS}

Baseline plethysmographic measurements of end expiratory thoracic gas volume (TGV) and initial inspiratory airways resistance (Raw) from pressureflow curves ${ }^{1314}$ were made by methods previously described. Specific airways resistance (sRaw) was calculated from the values of TGV and Raw. Reference values were taken from Stocks, ${ }^{7}$ with modifications for instrumental deadspace.

Forced, partial expiratory flow-volume (PEFV) curves were obtained as described previously ${ }^{12}$ while the infant lay supine, asleep, breathing through a face mask and $19 \mathrm{~mm}$ screen pneumotachograph (with Validyne MP45 pressure transducer). Briefly, they wore a flexible pressure jacket (available from the Department of Medical Engineering, Royal Postgraduate Medical School), which extended from sternal notch to upper thighs; this was rapidly inflated (in under $100 \mathrm{~ms})$ to $35( \pm 5) \mathrm{cm} \mathrm{H}_{2} \mathrm{O}$ from a pressurised tank by throwing a three way tap at end inspiration, during a period of regular breathing, to give a forced expiratory manoeuvre. Inflation was timed by inspecting an oscilloscope display of flow and volume. Expiratory flow was integrated to give volume. The maximum flow (V́max) at a volume equal to the end tidal point determined from the three previous regular breaths (the functional residual capacity, FRC) was recorded (V́maxFRC) for three to six jacket inflations at 30 second intervals. The mean of several technically satisfactory values ${ }^{12}$ was used. The mean peak expiratory flow (PEF) was also calculated.

\section{BRONCHODILATOR ADMINISTRATION}

After we had obtained baseline flow-volume curves and performed plethysmography, a control solution of nebulised normal saline $(2.5 \mathrm{ml})$ was given by Turrent nebuliser (Medic-Aid), with an airflow of $61 \mathrm{~min}^{-1}$. The nebuliser output was measured as $0.21 \mathrm{ml} \mathrm{min}^{-1}$. Several flow-volume curves were col- lected after 10 minutes. Salbutamol $(2.5 \mathrm{mg}$ in $2.5 \mathrm{ml}$ saline) was then given and full lung function tests were repeated after a 15 minute interval. Because of the duration of a full set of observations (up to two hours), some infants awoke before completion, leading to incomplete data or, on occasion, causing the investigations to be abandoned. In particular, reliable measurements of TGV and airway resistance were obtained at the end of the study in only 10 patients.

\section{ANALYSIS}

Paired $t$ tests were used to assess the overall effect of salbutamol on the physiological variables. The significance of individual responses to salbutamol was assessed by reference to the confidence limits for VmaxFRC and PEF determined from the baseline measurements for each individual.

\section{Results}

Initial lung function values confirmed the presence of appreciable airways obstruction (table 1). In particular the mean value of sRaw was 3.7 times the normal value of $35 \mathrm{~cm} \mathrm{H}_{2} \mathrm{O}$.s while VmaxFRC and PEF were reduced to $36 \%$ and $65 \%$ of their predicted values. ${ }^{12}$ Only four infants had a normal value of sRaw before study, and all of these were in the upper half of the normal range.

After nebulised saline there was no significant mean change in VmaxFRC or PEF (table 2). Nebulised salbutamol produced a significant fall in mean $\operatorname{VmaxFRC}(t=2 \cdot 35)$ but no change in mean PEF or in sRaw (table 2).

Examination of the individual results showed that most infants had a significant decline in V'maxFRC both after saline and after salbutamol (table 3, fig 1). There were no notable trends in the PEF response (table 3). In conjunction with change in the measured values of VmaxFRC, there were changes in the shape of PEFV curves after salbutamol. A decline in VmaxFRC was associated with increased convexity of the curve towards the axes (fig 2a). With improvement in VmaxFRC the PEFV curve tended to become straighter and to shift away from the tidal flow-volume curve (fig 2b).

There were no differences in the responses between the eight infants over 8 months and those under 8 months, or between those with and those without a history of bronchiolitis or of neonatal mechanical ventilation or a family history of atopic disease.

Five out of 72 sets of flow-volume data were based on less than three technically satisfactory observations. Technical problems during the flow-volume procedure, which led to unsatisfactory curves, included irregular breathing, glottic closure during expiration, and tidal and maximum flow-volume 
Table 1 Baseline lung function

\begin{tabular}{llc}
\hline & $\begin{array}{l}\text { No of } \\
\text { patients }\end{array}$ & $\begin{array}{l}\text { Mean (SD) } \\
\text { (\% reference value) }\end{array}$ \\
\hline Thoracic gas volume & 17 & $95 \cdot 2(31)$ \\
Airway conductance & 14 & $35 \cdot 3(15)$ \\
Specific airway resistance & 14 & $374(270)$ \\
VmaxFRC & 18 & $35.8(23)$ \\
Peak expiratory flow* & 18 & $64.5(14)$
\end{tabular}

*Based on predicted value of thoracic gas volume. ${ }^{12}$

VmaxFRC-maximum expiratory flow at functional residual capacity.

Table 2 Response to nebulised salbutamol (means with standard deviations in parentheses)

\begin{tabular}{|c|c|c|c|}
\hline & $\begin{array}{l}\text { Before } \\
\text { inhalation }\end{array}$ & $\begin{array}{l}\text { After } \\
\text { saline }\end{array}$ & $\begin{array}{l}\text { After } \\
\text { salbutamol }\end{array}$ \\
\hline $\begin{array}{l}\dot{V} \operatorname{maxFRC}\left(\mathrm{ml} \mathrm{s}^{-1}\right) \\
\operatorname{PEF}\left(\mathrm{ml} \mathrm{s}^{-1}\right) \\
\text { sRaw }\left(\mathrm{cm} \mathrm{H}_{2} \mathrm{Os}\right) \dagger\end{array}$ & $\begin{array}{l}103(81) \\
283(86) \\
14 \cdot 6(10)\end{array}$ & $\begin{array}{r}96(95) \\
271(81) \\
-\end{array}$ & $\begin{array}{c}85(81)^{*} \\
282(80) \\
12 \cdot 3(7)\end{array}$ \\
\hline
\end{tabular}

*Significantly different from pretreatment value $(p<0.05)$, based on paired $t$ test (no other differences were statistically significant).

tBased on 10 pairs of values.

VmaxFRC - maximum expiratory flow at functional residual capacity; PEF-peak expiratory flow; sRaw-specific airways resistance.

curves coinciding at FRC. Several patients reported here awoke briefly during the protocol.

\section{Discussion}

In a mixed group of 18 recurrently wheezy infants we have found a significant decline in forced expiratory flow rate after adminstration of nebulised salbutamol. At the same time we found, as have many before us, ${ }^{1-4}$ no significant change in the value of airway resistance, as measured during quiet tidal breathing. This apparently paradoxical response to a nebulised sympathomimetic drug could be of great clinical importance because of wheezy infants, unlike older patients with airways obstruction, appear to use forced expiration during tidal breathing, especially when they are particularly sick (personal observations). Since we have used a comparatively new test of infant lung function, it is important to question the

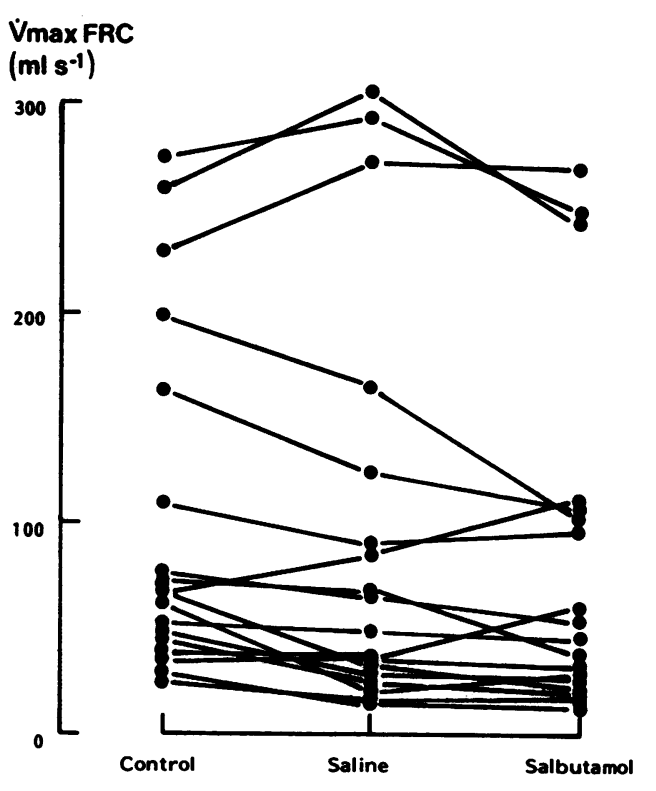

Fig 1 Individual values of maximum flow at functional residual capacity ( $\dot{\text { VmaxFRC}}$ ) before and after nebulised saline and salbutamol.

reliability of our findings before we consider the pharmacological and clinical implications.

\section{TECHNICAL ASPECTS}

Forced expiratory flow-volume curves have been widely used in older subjects to assess airway function. Their great merit is that, provided certain precautions are taken, ${ }^{12}$ they reveal details of intrathoracic airway function, independently of the upper airways. There are several reports of their use in infancy. ${ }^{11} 1215-17$

The accurate analysis of flow-volume curves demands knowledge of the lung volume. Although we reported the baseline TGV for our infants on the day of the study (table 1), we have little confidence in the accuracy of this plethysmographic measurement in wheezy infants. In the past we have noted a strong

Table 3 Individual responses

\begin{tabular}{|c|c|c|c|c|c|c|}
\hline & \multicolumn{3}{|l|}{ Saline } & \multicolumn{3}{|l|}{ Salbutamol } \\
\hline & Improved & No change & Worse & Improved & No change & Worse \\
\hline $\begin{array}{l}\text { V́maxFRC } \\
\text { PEF }\end{array}$ & $\begin{array}{l}2 \\
1\end{array}$ & $\begin{array}{r}6 \\
11\end{array}$ & $\begin{array}{r}10 \\
6\end{array}$ & $\begin{array}{l}2 \\
4\end{array}$ & $\begin{array}{r}3 \\
11\end{array}$ & $\begin{array}{r}13 \\
3\end{array}$ \\
\hline
\end{tabular}

Abbreviations as in table 2 . 

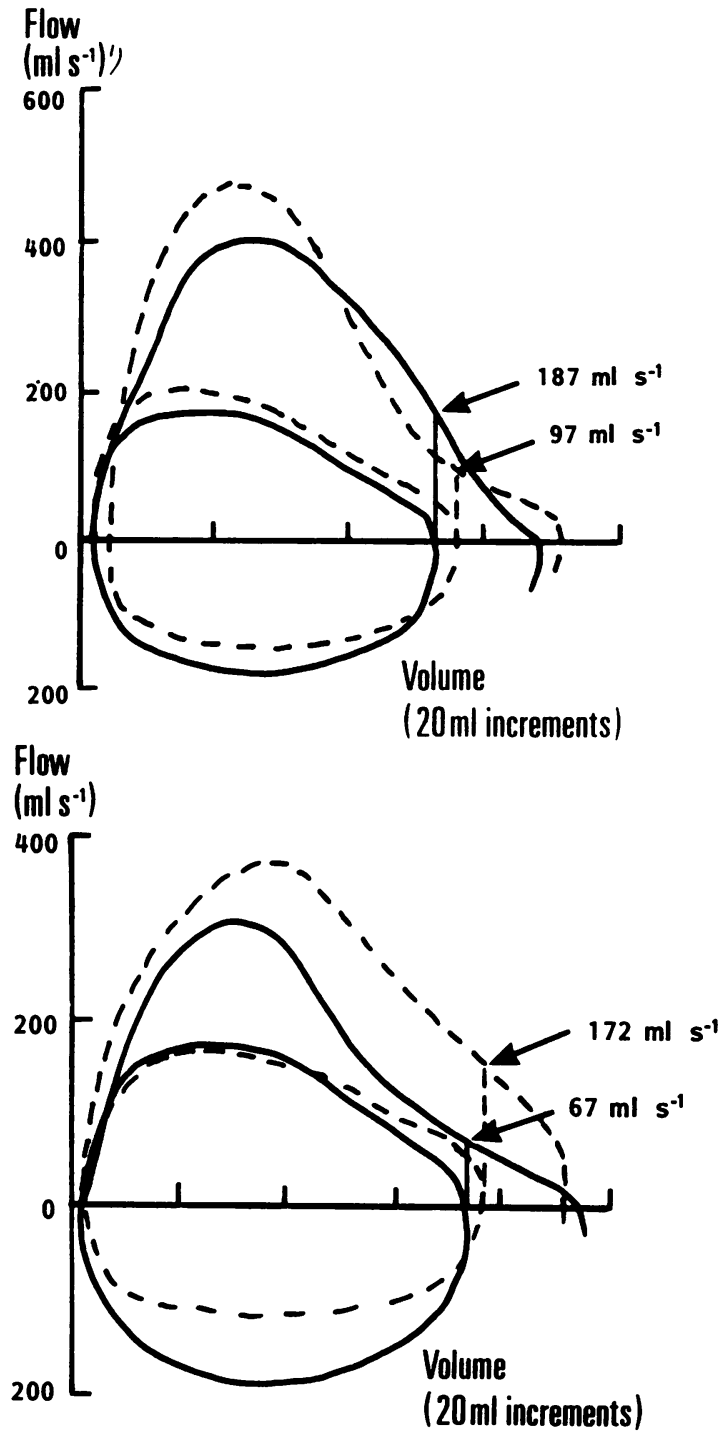

Fig 2 Flow-volume curves before (solid lines) and after (broken lines) nebulised salbutamol for two infants. Each forced expiratory flow-volume curve is shown with its preceding tidal curve, with values of maximum flow at functional residual capacity ( $\dot{V}$ max FRC). Changes in volume are referred to end inspiratory lung volume. (Above) Girl aged 15 months whose airway function deteriorated after salbutamol. (Below) Boy aged 9 months who improved after salbutamol.

tendency for TGV to be underestimated, even in clinically hyperinflated babies (Wong et al, personal observations). A recent study has confirmed these observations, suggesting that TGV measurements may be inaccurate in infants with airways obstruction. ${ }^{18}$
In older subjects bronchodilator treatment usually increases $\dot{V} \max$ at a given absolute lung volume but reduces FRC; the net effect is usually that $\dot{V}$ max is increased at the new FRC, but the increase is smaller than would be found if $\dot{V}$ max were compared at the same absolute lung volume before and after administration of bronchodilator. Because we could not accurately measure change in FRC after salbutamol, we cannot exclude the possibility that the small decline in VmaxFRC in our infants merely reflects a reduction in end-tidal volume; but of course this still indicates a deterioration in forced expiratory flow in the tidal breathing range. Two recent independent reports substantiate the paradoxical effect of nebulised salbutamol in wheezy infants, with $23 \%^{16}$ and $26 \%^{17}$ reduction in VmaxFRC. In our study V́maxFRC declined by $17 \%$.

In support of the numerical analysis of flow-volume curves, there was a corresponding change in the shape of the curves (fig 2). The change in shape that accompanied a fall in VmaxfrC (fig 2a) makes it unlikely that inspiratory effort against the jacket caused the decline in VmaxFRc. If this had been the case, the terminal segment of the PEFV curve would have become concave to the axes, as we have previously found in curves truncated by inspiratory effort. ${ }^{12}$

A reduction in forced expiratory flow rate after bronchodilator treatment, without an increase in airways resistance during quiet breathing, has been previously found in other chronic airway disorders. ${ }^{19-21}$ The explanation for this depends on the relative effects of bronchodilator drugs on airway compliance (by altering smooth muscle tone) and on airway calibre. An increase in airway compliance due to a decrease in airway smooth muscle tone will tend to diminish maximum flow rates at low lung volumes, since flow is limited by (among other factors) the properties of the airway wall. ${ }^{22}$ If intrathoracic airway calibre is not coincidentally improved by bronchodilator treatment, then the net effect of these drugs will be little or no improvement in overall airway resistance or lung volume during quiet breathing, but a decline in end expiratory flow rates during forced expiration. We have recently shown the opposite effect in response to low concentrations of the bronchoconstrictor agent histamine in some wheezy infants. ${ }^{23}$ There the lowest concentrations of nebulised histamine occasionally caused a rise in VmaxFRC. Higher concentrations had the more expected effect, with a fall in VंmaxFRc. In this case a fall in airway compliance, without change in calibre, could provide the explanation for the paradoxical response to low histamine concentrations.

Although we have found PEF to be a reproducible index of forced flow in infants, ${ }^{12}$ it is difficult to inter- 
pret the values obtained before and after salbutamol, which we have reported here for completeness. The "airway contribution" to a partial expiratory flow-volume curve may be quite large, and the size of this artefact may change with the level of airway obstruction. ${ }^{24}$ In addition, PEF may be influenced by resistance changes in the upper airway.

\section{PHARMACOLOGICAL AGENTS}

The technique of salbutamol administration was clearly important in these nose breathing infants. We gave a dose of salbutamol that was effective in older children. Although a large proportion of the nebulised drug must be deposited in the nasal passages, in contrast to the oropharynx in older children inhaling via a mouthpiece, the adequacy of jet nebulisation for administration of drugs to infants has been shown by the bronchoconstrictor effect of nebulised histamine ${ }^{24}$ and carbachol ${ }^{2526}$ administered by the same route.

The action of salbutamol, albeit an adverse effect in most of the infants, is a clear indication that there are functional $\beta_{2}$ adrenergic receptors in the airways. Our data may explain the clinical failure of bronchodilator treatment in wheezy infants. If the main cause of airway narrowing in the population is not excessive smooth muscle tone but factors such as airway inflammation or oedema, then any reduction in airway smooth muscle tone may have the adverse effect of increasing airway compliance, and hence cause a decrease in flow as described above. The apparent response of babies with acute bronchiolitis only to a combination of corticosteroids and salbutamol ${ }^{5}$ is consistent with this dual explanation of airways obstruction in wheezy infants.

\section{CLINICAL IMPLICATIONS}

The results of this study could have important implications not only for the clinical management of wheezy infants but also for the investigation of their airway physiology. If the effect of salbutamol is likely to be adverse in some infants, then we need a means of identifying such patients. It may be possible, as in elderly patients with chronic airway disease, to dissect out the poorly reversible from the reversible elements by means of high dose corticosteroid treatment.

The clinical consequences of increasing expiratory obstruction in an infant with severe airway obstruction could be critical. An increase in the work of breathing and a decline in arterial oxygenation may be expected. We have recently been able to monitor transcutaneous oxygen tension $\left(\mathrm{PaO}_{2}\right)$ after salbutamol administration in wheezy infants and have shown that there may be a decline of around $2 \mathrm{kPa}$ persisting for up to 20 minutes (unpublished observations). While a transient decline in arterial $\mathrm{Po}_{2}$ may occur in older subjects too, usually rapid broncho- $\vec{F}$ dilatation more than compensates for this. It may be $\stackrel{\overbrace{}}{\stackrel{2}{2}}$ desirable to monitor transcutaneous $\mathrm{Po}_{2}$ or oxygen saturation during bronchodilator administration in ill $\frac{\bar{c}}{\bar{c}}$ wheezy infants, and there may be a case for giving $\vec{\nabla}$ oxygen to avoid adverse effects in the event of a $\triangle$ paradoxical response to the bronchodilator.

The results obtained with the PEFV manoeuvre $\vec{\bullet}$ may have important implications for the physiological assessment of bronchoactive agents in $\vec{\omega}$ infants. Plethysmographic measurements of lung vol- $\stackrel{\circ}{?}$ ume and Raw are technically difficult and may not $\vec{x}$ provide clinically relevant data. ${ }^{18}$ Not only is Raw $\vec{N}$ affected by nasal obstruction, but its measurement i under conditions of sedation and quiet breathing does $\infty_{\infty}^{\circ}$ not mimic the conditions that are found during tachy- 0 pnoea and forced breathing in an acutely wheezy infant. The PEFV manoeuvre goes some way towards T replicating the clinical situation, and as we have $\frac{\mathbb{D}}{0}$ shown, may give contrasting results.

We are grateful for technical help to Mr Tim Demis, $\vec{\bullet}$ Mr Norman Levy, and Mr Jimmy Messeguer. The $\stackrel{\infty}{v}$ work was supported by the Asthma Research Council and Hammersmith and Queen Charlotte's Special Health Authority.

\section{References}

1 Lenney W, Milner AD. At what age do bronchodilator drugs work? Arch Dis Child 1978;58:532-5.

2 Stokes GM, Milner AD, Hodges IGC, Eliphick MC, Henry RL. Nebulized therapy in acute severe bronchiolitis in infancy. Arch Dis Child 1983;58:279-82.

3 Henry RL, Hiller EJ, Milner AD, Hodges IGC, Stokes GM. Nebulized ipratropium bromide and sodium cromoglycate in the first two years of life. Arch Dis Child 1984;59:54-7.

4 Henry RL, Milner AD, Stokes GM. Ineffectiveness of ipratropium bromide in acute bronchiolitis. Arch Dis Child 1983;58:925-6.

5 Tal A, Bavilski C, Yohali D, Beardman JE, Gorodischer 윽 $R$, Moses SW. Dexamethasone and salbutamol in the treatment of acute wheezing in infants. Pediatrics 을 1983;71:13-8.

6 Silverman M. Bronchodilator for wheezy infants? Arch $\widehat{乛}$ Dis Child 1984;59:84-7.

7 Stocks J. The functional growth of the lung during the first year of life. Early Human Development $\omega$ 1977;1:285-309.

8 Higenbottam $T$. Narrowing of the glottis opening in 0 humans associated with experimentally induced $\frac{C}{\mathscr{D}}$ bronchoconstriction. J Appl Physiol 1980;49:403-7.

9 England SJ, Ho V, Zamel N. Laryngeal constriction in $\tau$ normal humans during experimentally induced bron- $\bar{O}$ choconstriction. J Appl Physiol 1985;58:352-6.

10 Mygind N. Mediators of nasal allergy. J Allergy Clin $\frac{\Omega}{\mathbb{D}}$ Immunol 1982;70:149-59.

11 Taussig LM, Landau LI, Godfrey S, Arad I. Deter- 
minants of forced expiratory flows in newborn infants. J Appl Physiol 1982;53:1220-7.

12 Silverman M, Prendiville A, Green S. Partial expiratory flow-volume curves in infancy: technical aspects. Bull Physiopathol Respir 1986;22:257-62.

13 Stocks J, Levy NM, Godfrey S. A new apparatus for the accurate measurement of airway resistance in infancy. J Appl Physiol 1977;43:155-9.

14 Stocks J, Thomson A, Silverman M. The numerical analysis of pressure-flow curves in infancy. Pediatr Pulmonol 1985;1:19-26.

15 Godfrey S, Bar-Yishay E, Arad I, Landau LI, Taussig LM. Flow-volume curves in infants with lung disease. Pediatrics 1983;72:517-22.

16 Hughes D, LeSoeuf P, Landau L. Bronchodilator responsiveness in bronchiolitis. Austr Paediatr $J$ 1984;20:337.

17 Spier S, Lapierre SG, Lamarre A. Response to salbutamol during 1st or 2 nd episode of wheezing in infancy [abstract]. Am Rev Respir Dis 1985;131:A259.

18 Godfrey S, Beardsmore CS, Maayon C, Bar-Yishay E. Can thoracic gas volume be measured in infants with airways obstruction? Ann Rev Respir Dis 1986;133:245-51.
19 Bouhuys A, Van de Woestijne KP. Mechanical consequences of airway smooth muscle relaxation. $J$ Appl Physiol 1971;30:670-6.

20 Bouhuys A, Van de Woestijne KP, Kane G, Van Wayenburg J. Respiratory mechanics and dust exposure in byssinosis. $J$ Clin Invest 1970;49:106-18.

21 Zapletal A, Motoyama EK, Gibson LE, Bouhuys A. Pulmonary mechanics in asthma and cystic fibrosis. Paediatrics 1971;48:64-72.

22 Hyatt RE. Expiratory flow limitation. J Appl Physiol 1983; 55;1-8.

23 Prendiville A, Green S, Silverman M. Bronchial responsiveness to histamine in wheezy infants. Thorax 1987;42:92-9.

24 Knudson RJ, Mead J, Knudson DE. Contribution of airway collapse to supramaximal expiratory flows. $J$ Appl Physiol 1974;36:653-67.

25 Benoist PR, Volanthen MC, Rufin P, Jean R. Apport des tests de provocation bronchique chez le nourrisson. Respiration 1981;42(suppl 1):51-2.

26 Gutkowski P, Kowalski J. Zentrale Atemregulation im bronchialen provokation Test bei Sauglingen und Kleinkindern mit obstruktiver Bronchitis. Atemw Lungenkrank Jahrgang 1984;10:S517-21. 